Informatives Lehrbuch über das Regieren

Helms, Ludger: Regierungsorganisation und politische Führung in Deutschland (Grundwissen Politik, Band 38), VS Verlag für Sozialwissenschaften, Wiesbaden 2005, 237 Seiten, $€ 19,90$.

Im Lichte der derzeitigen, teilweise geradezu modisch erscheinenden Diskussion um „governance“ im Sinne des „Regierens ohne Regierung“ mutet die Auseinandersetzung mit dem Thema „Regierungsorganisation und politische Führung“, die sich, wie der Autor bekennt (S. 48), ganz bewusst einer „government“-Perspektive verpflichtet fühlt, beinahe antiquiert an. Und in der Tat: Sieht man von den in jüngerer Zeit publizierten Studien aus dem Bereich der Koalitionsforschung, die eine gewisse Blütezeit erlebt, einmal $\mathrm{ab}$, fristet die politikwissenschaftliche Beschäftigung mit der Institution „Regierung“ verglichen etwa mit der Parteien- oder der Parlamentarismusforschung - eher ein Mauerblümchendasein. Dies erscheint umso erstaunlicher, als die auf den Output des politischen Systems gerichteten Erwartungen der Bürger natürlich in erster Linie auf die jeweilige Regierung orientiert sind. So trivial die Erkenntnis auch sein mag, mit der Ludger Helms sein Lehrbuch einleitet, dass nämlich Regierungen zu den zentralen Einrichtungen moderner Demokratien gehören, so liefert sie doch die einsichtige Begründung dafür, die Frage nach der politischen Führung in Form eines neu konzipierten Lehrbuchs vertiefend auszuleuchten.

Helms nähert sich seinem Gegenstand, indem er die Rolle der Exekutive im historischen Wandel, beginnend mit dem Absolutismus, skizziert, um anschließend die „Position der Exekutive in unterschiedlichen Grundmodellen liberaler Demokratie“ zu verorten. Auf dieser Grundlage gelingt ihm dann eine knappe, aber sehr instruktive Synopse über die politikwissenschaftlichen Annäherungen an den Forschungsgegenstand „Exekutive“.

Die eigentliche Auseinandersetzung mit der Regierungsorganisation in Deutschland beginnt der Autor mit Kapitel 3, in dem er die Grundlagen des Regierens in der Bundesrepublik in historischer, verfassungsrechtlicher und politisch-kultureller Perspektive umreißt. Herausgearbeitet wird hier unter anderem der Vorrang, den das Kanzlerprinzip vor den anderen Grundsätzen der Regierungsorganisation genießt, was wiederum nahe legt, im folgenden Kapitel das politische Profil und die Karrierewege der deutschen Bundeskanzler von Konrad Adenauer bis Gerhard Schröder nachzuzeichnen. Warum dieses Kapitel allerdings - anders als alle anderen Teile des Buches, in denen Helms mit umfassenden, akribisch recherchierten Literaturnach- und -hinweisen aufwarten kann - völlig ohne entsprechende Belege bleibt, erscheint wenig einsichtig.

Seine Stärken entfaltet das Buch in den folgenden Kapiteln, in welchen zunächst die intragouvernementalen Strukturen und Entscheidungsprozesse analysiert und sodann die Reichweite der politischen Führung auf der Ebene des politischen Gesamtsystems thematisiert werden. Hinsichtlich letzterer werden zunächst die parlamentarische („Kanzler und der Bundestag“) und die parteipolitische Arena („Kanzler und ihre Parteien“) ausgeleuchtet. Dem folgend lässt sich Helms von dem von George Tsebelis entwickelten „Vetospieler-Theorem“ inspirieren, das er bereits einleitend (S. 25 f.) kritisch, aber auf Grund seines heuristischen Wertes letztlich doch zustimmend referiert hat. Als potenzielle „Veto- 
spieler" identifiziert der Verfasser den Bundesrat, das Bundesverfassungsgericht, (früher) die Bundesbank und (heute) die Europäische Zentralbank sowie die Interessengruppen, wobei er deren jeweiligen Einfluss auf das Regierungshandeln kenntnisreich einzuschätzen versteht. Weniger als „Veto-“ denn als „Mitspieler" erscheint der ebenfalls in diesem Kapitel abgehandelte Bundespräsident. Indem Helms aus der besonderen Perspektive der an Gestaltungsspielräumen interessierten Bundesregierung sämtliche Verfassungsorgane einschließlich ihrer jeweiligen Handlungslogik anspricht, gelingt ihm hier eine höchst lesenswerte, weil unkonventionelle Einführung in die Funktionsmechanismen und „Spielregeln" unseres politischen Systems, wie man sie in den herkömmlichen Lehrbüchern nicht findet.

Recht bemüht wirkt dagegen die folgende, als „Exkurs“ angelegte Darstellung der Regierungsorganisation in den Ländern, die wohl nur der oft zitierten „Vollständigkeit halber" Berücksichtigung fand und - wie im Übrigen auch die anderen drei im Buch platzierten Exkurse - den Lesefluss eher stört. Gleichwohl wendet sich der Leser wiederum mit Gewinn dem Abschlusskapitel zu, das den roten Faden wieder aufnimmt, indem die Besonderheiten des deutschen Modells politischer Führung im internationalen Vergleich - verständlicherweise eben ausschließlich in Bezug auf die Bundesebene - herausgearbeitet werden.

Misst man Helms Werk an dem Anspruch, Grundwissen zu vermitteln, dann erfüllt es diesen ohne Mühe. Dem Verfasser wäre zu wünschen, dass er in nicht allzu ferner $\mathrm{Zu}$ kunft Gelegenheit erhält, sein Buch für eine Folgeauflage zu aktualisieren, denn die zweite Große Koalition, die in der Bundesrepublik Deutschland seit November 2005 amtiert, bricht doch mit so mancher, von Helms durchaus zu Recht identifizierten Konvention. Ein Vergleich der Entstehungsbedingungen, Binnenstrukturen und Handlungslogiken beider Großer Koalitionen würde den Band gewiss bereichern.

Heinrich Pehle

\section{Anspruchsvolles Praxishandbuch für das Lernen von Politik}

Reinhardt, Sibylle: Politikdidaktik. Praxishandbuch für die Sekundarstufe I und II, Cornelsen Verlag Scriptor, Berlin 2005, 254 Seiten, € 19,95.

Sibylle Reinhardts Buch steht unter einem mehrfachen Praxisanspruch: Nicht nur im Untertitel wird von einem „Praxishandbuch“ gesprochen, auch das Vorwort beginnt mit dem Satz: „Diese Politik-Didaktik will das theoriegeleitete praktische Handeln im Unterricht fördern.“ (S. 8) Die Systematik des Bandes umfasst die Lehrerrolle, die Ziele („Demokratie-Lernen"), die Sozialisation sowie die Institution Schule (Teil I), zentrale fachdidaktische Prinzipien als „Herzstück des Buches“ (II), „Wissenschaftspropädeutik“ (III), Lernarrangements (IV) sowie ein Planungskonzept (V).

Wie wird dem Praxisanspruch Genüge getan? Neben bekannten Lehrstücken aus der Politikdidaktik (Lehrerrolle, Beutelsbacher Konsens usw.) erscheint die Frage nach den 